\title{
DESENVOLVIMENTO DE FRUTOS E SEMENTES DE TAMARINDO'
}

\author{
KÁTIA CRISTINA DE OLIVEIRA GURJÃO², RISELANE DE LUCENA ALCÂNTARA BRUNO², FRANCISCO DE \\ ASSIS CARDOSO ALMEIDA ${ }^{4}$, WALTER ESFRAIN PEREIRA ${ }^{5}$, GENILDO BANDEIRA BRUNO ${ }^{6}$
}

\begin{abstract}
RESUMO - O objetivo deste trabalho foi avaliar as mudanças físicas e fisiológicas ocorridas durante o desenvolvimento de frutos e sementes de tamarindo. Foram selecionadas árvores de um pomar localizado na Escola Agrotécnica Federal de Sousa-PB, com 50\% das inflorescências em antese, cujos ramos, contendo flores abertas, foram marcados, e as colheitas realizadas aos 20; 40; 70; 100; 130; 160; 190; 220; 250; 270 e 280 dias após a antese. A cada colheita, os frutos e as sementes foram submetidos às seguintes avaliações: comprimento, largura e espessura dos frutos e sementes (cm); massa da matéria seca dos frutos e sementes (g); teor de água das sementes (\%); teste de germinação (\%). As plantas de tamarindo levaram aproximadamente 280 dias após a antese para completar o ciclo desde a floração até a colheita, período representado pelo crescimento, maturação e o amadurecimento dos frutos. $\mathrm{O}$ crescimento dos frutos de tamarindo pode ser descrito por um modelo sigmoidal simples. A maturação fisiológica dos frutos de tamarindo ocorreu no período entre 270 e 280 dias após a antese, coincidindo com o desprendimento natural da planta-mãe e a maturação das sementes, aos 277 dias após a antese.
\end{abstract}

Termos para indexação: Tamarindus indica L., maturação fisiológica, sementes.

\section{DEVELOPMENT OF TAMARIND FRUITS AND SEEDS}

\begin{abstract}
The objective of this work was to evaluate the physical and physiologic changes happened during the development of tamarind fruits and seeds. Trees of a located orchard were selected at the Federal Agrothechnic School of Sousa-PB, with 50\% of the inflorescences in anthesis, which branches, containing open flowers, were marked and the crops were accomplished to the 20, 40, 70, 100, 130, 160, 190, 220, 250, 270 and 280 days after anthesis. To each crop, fruits and seeds were submitted to the following evaluations: length, width and thickness of fruits and seeds (cm); fruits and seeds dry matter mass (g); seeds water content (\%) and germination test (\%).Tamarind plants took approximately 280 days after anthesis to complete the cycle from blooming to crop, period represented by fruits' growth, maturation and ripening. Tamarind fruits growth can be described by a simple sigmoidal model. Tamarind fruits physiologic maturation happened in the period between 270 and 280 days after anthesis, which coincided with the plant mother's natural detachment and seeds maturation to the 277 days after anthesis.

Index terms: Tamarindus indica L., physiologic maturation, seeds.
\end{abstract}

\section{INTRODUÇÃo}

O tamarindo pertence à família Leguminosae, originário da África tropical, de onde se dispersou por todas as regiões tropicais. É uma árvore frutífera e bastante decorativa, podendo chegar aos 25 $\mathrm{m}$ de altura. Seu fruto é uma vagem alongada, com 5 a $15 \mathrm{~cm}$ de comprimento, com casca pardo-escura, lenhosa e quebradiça, contendo 3 a 8 sementes envolvidas por uma polpa parda e ácida (Donadio, 1988). A utilização do tamarindo dá-se, principalmente, a partir da polpa, no preparo de doces, sorvetes, licores, sucos concentrados e ainda como tempero para arroz, carne, peixe e outros alimentos.

Estudos sobre o desenvolvimento de frutos e sementes são importantes para estabelecer estratégias de colheita e técnicas adequadas de armazenamento pós-colheita para aumentar a vida útil e, com isso, melhorar o aproveitamento do potencial de comercialização do fruto. Segundo Pantástico (1975), a determinação da maturidade de frutos pode ser feita por vários métodos, entre os quais, fenológicos (dias após a antese), observações visuais (cor da casca, tamanho e formato do fruto) e físicas (abscisão, densidade e firmeza). Porém, os resultados obtidos por esses métodos podem variar, dependendo do local de cultivo, cultivares e condições climáticas do ano de crescimento. Para Warrington et al. (1999), um dos índices mais utilizados na determinação do ponto de colheita é o número de dias desde a floração até o desenvolvimento pleno do fruto.

Para as sementes, o estudo do processo de desenvolvimento envolve observações sobre as modificações de natureza morfológica e fisiológica desde o momento da fecundação do óvulo até atingir a maturidade. As características normalmente estudadas são: tamanho, teor de água, conteúdo de massa seca, germinação e vigor, além de características bioquímicas que, analisadas em conjunto, permitem uma estimativa do estádio de maturação, possibilitando a identificação da maturidade fisiológica das sementes (Carvalho \& Nakagawa, 2000).

Por ser uma cultura pouco estudada, como é o caso do tamarindo, torna-se necessário o estudo do desenvolvimento de frutos e sementes, desde o início de sua formação até a colheita. Por esta razão, o objetivo deste trabalho foi avaliar as mudanças físicas e fisiológicas ocorridas durante o desenvolvimento de frutos e sementes de tamarindo, visando a obter subsídios na determinação do estádio de maturação mais adequado para a colheita e pós-colheita, favorecendo a comercialização.

\section{MATERIAL E MÉTODOS}

Este trabalho foi realizado de fevereiro a dezembro de 2003, utilizando árvores selecionadas de um pomar localizado na Escola Agrotécnica Federal de Sousa - PB, na zona fisiográfica do Sertão Paraibano, a 220 metros de altitude, de coordenadas geográficas latitude $6^{\circ} 45^{\prime} 33^{\prime \prime}$ sul e longitude $38^{\circ} 13^{\prime} 41^{\prime \prime}$ oeste, com temperatura média anual de $28^{\circ} \mathrm{C}$, umidade relativa de $60 \%$ e insolação anual de 3.058 horas/ano. As plantas selecionadas encontravam-se em plena produção e, após constatadas $50 \%$ das inflorescências em antese, foram marcadas, com fios de lã de cores diversas, em vários ramos contendo flores abertas. As avaliações foram realizadas aos 20; 40; 70; 100; 130; 160; 190; 220; 250; 270 e 280 dias após a antese.

A cada colheita, os frutos foram transportados para o Laboratório de Análise de Sementes, do Centro de Ciências Agrárias da Universidade Federal da Paraíba - CCA/UFPB, e submetidos às

\footnotetext{
${ }^{1}$ (Trabalho 128-2005). Recebido: 18-08-2005. Aceito para publicação: 27-07-2006.

${ }^{2}$ Escola Agrotécnica Federal de Sousa-PB, Av.Tancredo Neves s/n, Sousa-PB, katgurjao@zipmail.com.br

${ }^{3}$ UFPB/CCA, Depto. de Fitotecnia, CP22, Areia-PB, CEP: 58397-000, lane@cca.ufpb.br

${ }^{4}$ UFCG/CCT, DEAg, Av. AprígioVeloso, 882, Bodocongó, Campina Grande-PB, CEP 58109-970, almeida@ deag.ufcg.edu.br

${ }^{5}$ UFPB/CCA, Depto. de Ciências Fundamentais e Sociais, CP 22, Areia-PB, CEP: 58397-000, wep@cca.ufpb.br

${ }^{6}$ UFPB/CCA, Depto. de Fitotecnia, CP 22, Areia-PB, CEP: 58397-000, bruno@ cca.ufpb.br
} 
seguintes avaliações: Dimensões (comprimento, largura e espessura do fruto, $\mathbf{c m}$ ): determinados através de medições diretas com auxílio de um paquímetro; Massa da matéria seca do fruto (g): mediante secagem em estufa, a $65^{\circ} \mathrm{C}$, até peso constante (Instituto Adolfo Lutz,1985).

O delineamento utilizado foi o inteiramente casualizado, com quatro repetições de 10 frutos cada. As análises de comprimento, largura, espessura e massa da matéria seca do fruto, foram ajustadas à equação logística $\left(\mathrm{y}=\mathrm{a} / 1+\mathrm{b}^{*} \exp \left(-\mathrm{k}^{*} \mathrm{x}\right)\right)($ Richards, 1969), e as taxas de crescimento, obtidas pela derivada primeira da equação ajustada.

A extração das sementes dos frutos só foi possível aos 160 dias, quando estas foram submetidas às seguintes avaliações: Dimensões (comprimento, largura e espessura da semente, $\mathbf{c m}$ ): determinadas através de medições diretas com auxílio de um paquímetro; Teor de água (\%): com base no método-padrão da estufa $105^{\circ} \pm 3^{\circ} \mathrm{C}$, durante $24 \mathrm{~h}$, segundo as prescrições das Regras para Análise de Sementes (Brasil, 1992); Massa da matéria seca da semente (g): desenvolvida juntamente com o teor de água, antes e após a permanência das sementes em estufa, a $105^{\circ} \pm 3^{\circ} \mathrm{C}$, durante $24 \mathrm{~h}$ Teste de germinação: realizado no substrato de papel "Germitest", umedecido com 2,5 vezes o seu peso com água destilada e, em seguida, formados os rolos e colocados em câmaras tipo BOD, a $30^{\circ} \mathrm{C}$. A cada três dias após a semeadura, foram feitas observações para determinar o início e as porcentagens de sementes germinadas, com término das avaliações aos 30 dias.

O delineamento experimental utilizado foi o inteiramente casualizado, com quatro repetições de 20 sementes. Os dados obtidos foram submetidos à análise de variância e regressão, avaliando-se o efeito linear, quadrático e cúbico.

\section{RESULTADOS E DISCUSSÃO}

No ano de 2003, o início da floração dos tamarineiros, localizados na Escola Agrotécnica Federal de Sousa - PB, ocorreu no mês de janeiro, com plena floração em fevereiro. A formação do fruto do tamarindo ocorreu, em média, três dias após a antese, com início de formação da polpa aos 70 dias e sementes aos 130 dias. Pela dificuldade de separação da polpa, a extração das mesmas só foi possível aos 160 dias após a antese.

(a)
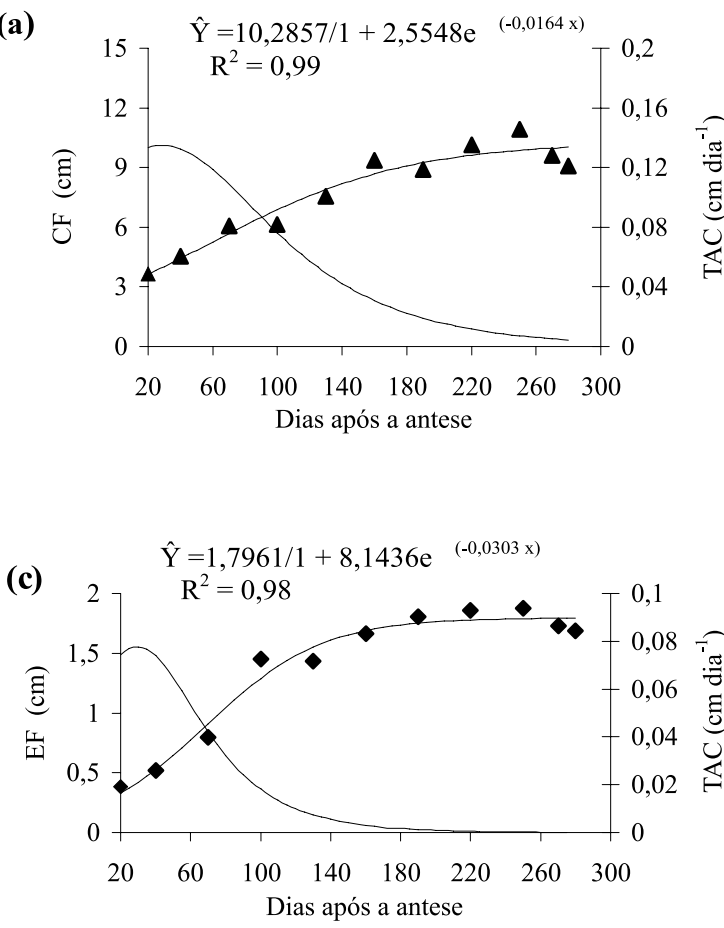

O tamarindo levou aproximadamente 280 dias após a antese para completar o ciclo, desde a floração até a colheita, período representado pelo crescimento, maturação e amadurecimento dos frutos (Figura 1). O amadurecimento pleno, dando início aos sinais de enfraquecimento da camada de abscisão do pecíolo como preparação para a liberação do fruto da planta-mãe, ocorreu entre 270 e 280 dias após a antese, momento utilizado para a realização da colheita dos frutos caídos ao solo e posterior consumo in natura e/ ou industrialização

O padrão de crescimento segue o modelo sigmoidal simples (Figura $1 \mathrm{a}, \mathrm{b}, \mathrm{c}, \mathrm{d}$ ), como também descreveu Hernández-Unzon \& Lakshminarayana (1982), em estudo com tamarindo, realizado no México.

Para o crescimento dos frutos, duas fases foram caracterizadas. A primeira estende-se até aproximadamente 120 dias após a antese, na qual o tamarindo chega a $74 \%(7,6 \mathrm{~cm})$ do seu comprimento máximo teórico. A largura e espessura (Figura 1 b e c) apresentaram comportamento similar; no entanto, com um desenvolvimento mais acentuado no primeiro período, em que se têm $90 \%(2,2 \mathrm{~cm})$ a $82 \%$ $(1,5 \mathrm{~cm})$, respectivamente, do valor máximo do fruto, considerando essas medidas. Este comportamento pode ser devido, segundo Hulme (1970), a um aumento em volume de células, que pode durar pouco tempo ou prolongar-se por várias semanas. Porém, a expansão celular pode continuar até o amadurecimento (Chitarra, 1994). A segunda fase estende-se dos 120 aos 280 dias após a antese e foi caracterizada por uma desaceleração na taxa de crescimento, onde os frutos apresentaram taxas mais baixas de aumento de comprimento, largura e espessura e início de grande acúmulo de massa da matéria seca (Figura 1d). Nesta fase, o comprimento, a largura e a espessura atingiram 97; 99 e $99 \%$ de seus valores máximos teóricos, respectivamente.

A massa da matéria seca do fruto (Figura 1d) apresentou três fases bem caracterizadas. A fase I, de crescimento lento até 80 dias após a antese, acumulando apenas $11 \%$ da massa seca teórica. A fase II, de crescimento mais acentuado, entre 80 a 180 dias, a massa seca passou de $11 \%$ a $87 \%$ do total. A fase III, de crescimento lento, de 180 dias até o final das avaliações, apresentou acúmulo de $13 \%$ do total da massa da matéria seca teórica. O aumento da massa da matéria seca pode ser explicado pela formação de proteínas, açúcares

(b)
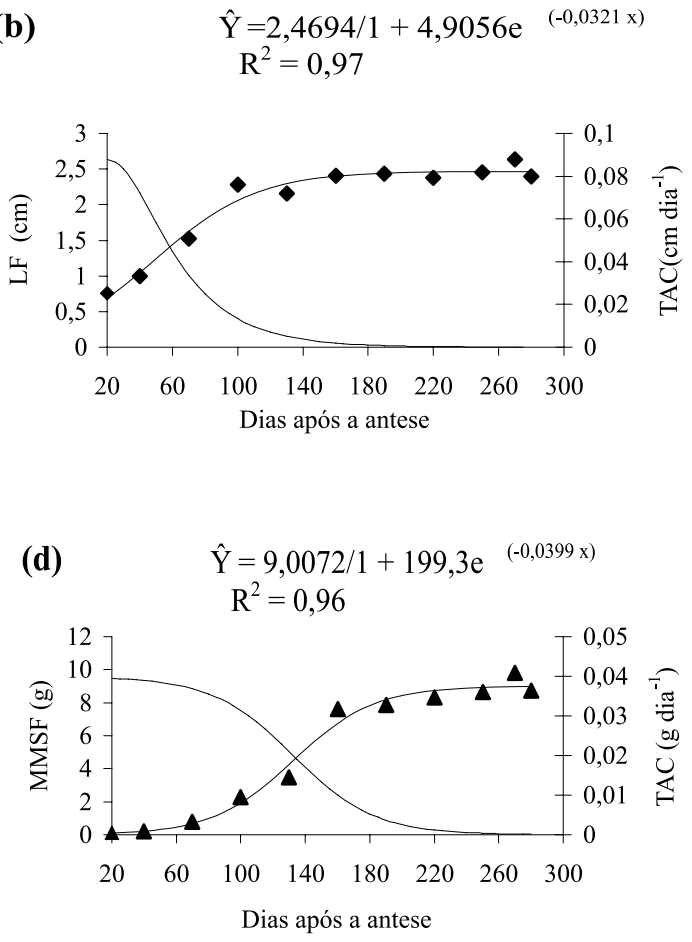

FIGURA 1- Comprimento (CF) (a), largura (LF) (b), espessura (EF) (c) e massa da matéria seca (MMSF) (d) de frutos de tamarindo durante o seu desenvolvimento.

Rev. Bras. Frutic., Jaboticabal - SP, v. 28, n. 3, p. 351-354, Dezembro 2006 
e outras substâncias acumuladas durante o desenvolvimento do fruto (Dias, 2001). Hernández-Unzon \& Lakshminarayana (1982) também observaram aumento da massa da matéria seca e dimensões do tamarindo durante o seu desenvolvimento

Observa-se, para todas as medidas consideradas no desenvolvimento do tamarindo, taxas de crescimento maiores no início do desenvolvimento, decrescendo posteriormente até o final das avaliações, onde o fruto não apresentava mais desenvolvimento, e essas taxas assumiram valores próximos de zero.

No tocante à evolução das dimensões das sementes dessa frutífera (Figura 2 a, b, c), entre 160 e 220 dias após a antese, à medida que as sementes se desenvolvem, ocorre um aumento nas suas dimensões, tanto em comprimento (Figura 2 a) como em largura (Figura 2 b) e espessura (Figura 2 c), até atingir o máximo, após o qual sofrem ligeiro declínio. Os máximos valores nas dimensões ocorreram na ordem de 231; 202 e 218 dias após a antese, quando as sementes de tamarindo mediam em torno de 2,0; 1,1 e 0,98 cm, respectivamente, de comprimento, largura e espessura. O padrão de crescimento das sementes foi semelhante ao descrito por Alves (2005) em sementes de sabiá, que aumentaram de tamanho rapidamente, atingindo o máximo aos 154 dias após a antese, período relativamente curto em relação à duração total do período de maturação.

As sementes de tamarindo apresentaram, aos 160 dias após a antese, um teor de água de $66 \%$ (Figura 2 d), alcançando o máximo (68\%) aos 176 dias, decrescendo lentamente até 190 dias após a antese, com queda acentuada até o final do período de avaliação. Entre 250 e 270 dias, o teor de água reduziu-se de $37 \%$ para $20 \%$, alcançando $11 \%$ aos 280 dias após a antese. O período de menor teor de água coincidiu com o máximo acúmulo de massa seca.

$\mathrm{O}$ alto teor de água inicial (66\%), verificado nas sementes, e seu posterior decréscimo, está relacionado com a importância da água nos processos de enchimento e maturação das sementes. Segundo Corvello et al. (1999), para que os produtos fotossintetizados nas folhas sejam depositados na semente em

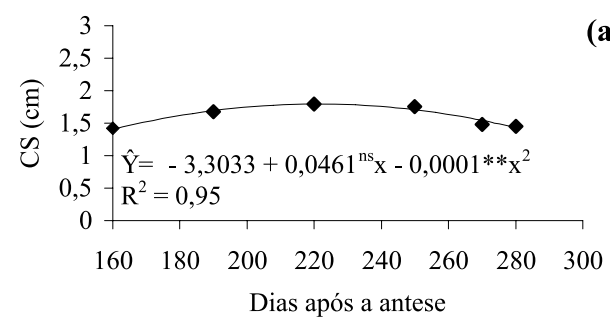

(a)
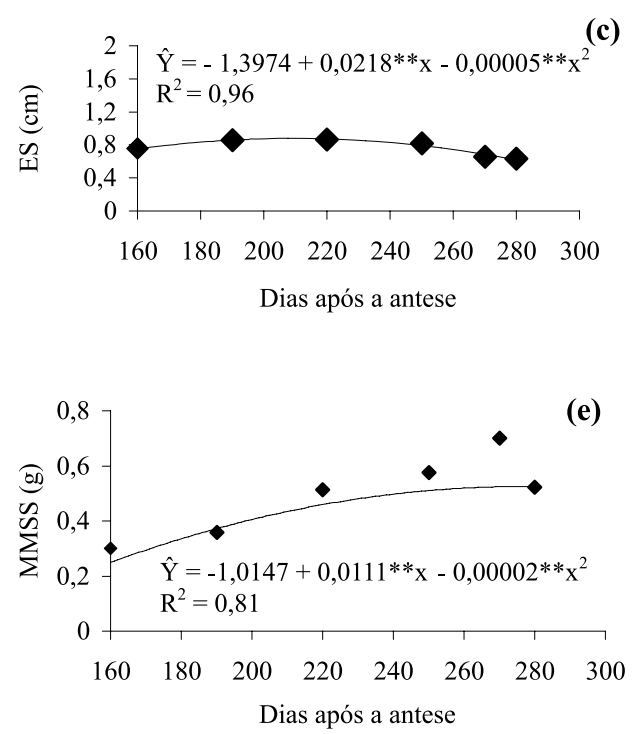

formação, sendo utilizado como material de construção e, posteriormente, como reserva, é necessário que esta mantenha elevado grau de umidade, o que ocorre até a massa seca atingir seu valor máximo, quando então se inicia uma rápida desidratação.

Em sementes de Dalbergia nigra, Martins \& Silva (1997) observaram que a redução no teor de água ocorreu de forma lenta e gradual até os 319 dias, quando, então, sofreu uma queda pronunciada, passando de $68,02 \%$ para $25,30 \%$, aos 335 dias, época em que as sementes atingiram a maturidade fisiológica. Para sementes de sabiá, Alves (2005) encontrou teores de água (82,1\%) aos 119 dias após a antese,com redução lenta até 147 dias, e a partir desta data, houve uma acentuada queda nesses valores.

Essa variação no teor de água também foi observada em mucuna-preta (Nakagawa et al., 2005); Cedrela fissilis (Corvello et al., 1999); Citharexylum montevidense (Leonhardt et al., 2001); Enterolobium contotisiliqquum (Borges et al., 1980).

Com relação à massa da matéria seca das sementes (Figura 2 e), estas apresentaram 0,23 g no início do período estudado, aumentando continuadamente com o grau de maturidade das sementes, atingindo valor máximo (0,53 g) aos 277 dias após a antese, diminuindo a partir deste período. Esse comportamento foi semelhante ao descrito por Carvalho \& Nakagawa (2000), que o acúmulo de massa seca em uma semente aumenta com o avanço da maturação, podendo, no final, sofrer pequeno decréscimo, como resultado de perdas pela respiração. Segundo os mesmos autores, a colheita deve ser realizada no ponto de máxima matéria seca, uma vez que, após este estádio de desenvolvimento, o fruto ficará na dependência das adversidades climáticas, podendo ganhar ou perder água, ou mesmo desencadear o processo de deterioração, principalmente em frutos secos. Geralmente, as sementes alcançam a máxima qualidade fisiológica no ponto de máxima massa seca (Dias, 2001). Barbosa et al. (1993) verificaram que as sementes de pêssego de ciclo mediano, tardio e bem tardio aumentam progressivamente o peso da matéria seca até a época de maturação dos frutos.

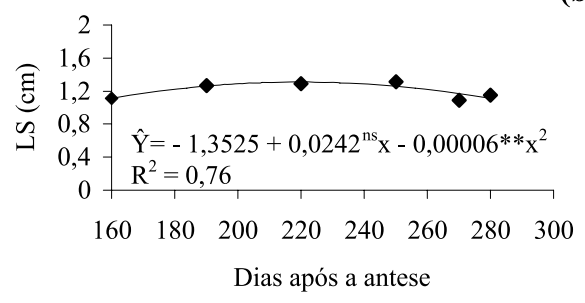

(b)

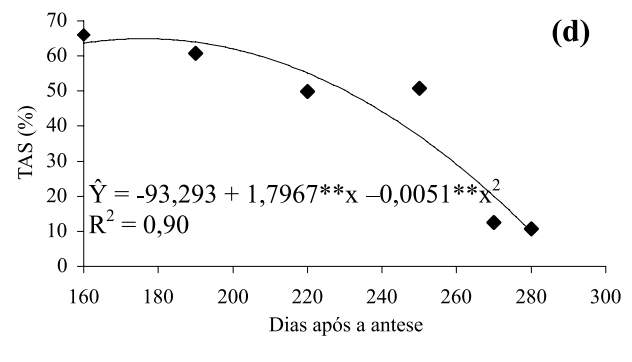

(f)

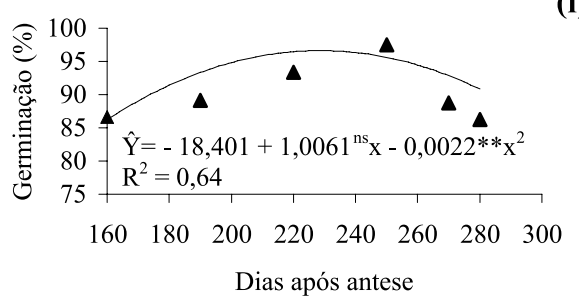

FIGURA 2 - Comprimento (CS) (a), largura (LS) (b), espessura (ES) (c), teor de água (TAS) (d), massa da matéria seca da semente (MMSS) (e) e germinação (f) de sementes de tamarindo durante o processo de desenvolvimento. 
Aos 160 dias após a antese, as sementes de tamarindo (Figura 2 f) já apresentavam elevada viabilidade (86,2\%), atingindo o máximo $(90,8 \%)$ aos 250 dias após a antese, registrando-se no final do período 90,3 \% de germinação. De acordo com estes resultados, percebe-se nitidamente que as sementes de tamarindo apresentaram alta viabilidade em todo o período de avaliação. Reis \& Salomão (1999) verificaram que o estádio de maturação dos frutos de Jenipa americana L. não compromete o poder germinativo das sementes, sendo possível o aproveitamento das mesmas provenientes de frutos imaturos. Comportamento semelhante foi observado em Vigna unguiculata (L.) Walp. cv Sempre-Verde (Morais et al., 2001a) e Glycine max L. (Morais et al., 2001b).

Analisando as variáveis de forma conjunta (Figura 2), tais dados indicam que a colheita das sementes de tamarindo pode ser realizada aos 277 dias após a antese, para a região em estudo, quando estas apresentam o maior acúmulo de massa seca e germinação superior a $90 \%$, momento em que, conforme já abordado anteriormente, se inicia um decréscimo acentuado no teor de água e dimensões da semente.

\section{CONCLUSÃO}

1) $\mathrm{O}$ crescimento dos frutos de tamarindo pode ser descrito por um modelo sigmoidal simples.

2) O comprimento, a largura e a espessura dos frutos apresentaram duas fases de crescimento.

3) A massa da matéria seca dos frutos apresentou três fases de crescimento.

4) A maturação fisiológica dos frutos de tamarindo ocorre no período entre 270 e 280 dias após a antese, coincidindo com o desprendimento natural dos frutos da planta-mãe (consumo in natura).

5) A maturidade fisiológica das sementes de tamarindo ocorre aos 277 dias após a antese para as condições ambientais da região estudada.

\section{REFERÊNCIAS}

ALVES, E.U; SADER, R.; BRUNO, R.L.A.; ALVES, A.U. Maturação de Sementes de Sabiá. Revista Brasileira de Sementes, Brasília, v.27,n.1, p.1-8, 2005.

BARBOSA,W.; OJIMA,M.; DALL'ORTO, F.A.C.; MARTINS,F.P.; LOVATE, A.A. Desenvolvimento dos Frutos e Sementes de Pêssegos Subtropicais de Diferentes Ciclos de Maturação. Pesquisa Agropecuária Brasileira, Brasília, v.28, n.6, p.701-707, 1993.

BORGES, E.E.L.; BORGES, R.C.G.; TELES, F.F.F. Avaliação da Maturação e dormência de sementes de orelha de negro. Revista Brasileira de Sementes, Brasília, v.2, n.2, p.29-32, 1980.

BRASIL. Ministério da Agricultura e Reforma Agrária. Regras para análise de sementes. Brasília, 1992.365p

CARVALHO, N. M.; NAKAGAWA, J. Sementes: ciência, tecnologia e produção. 4.ed. Jaboticabal: FUNEP, 2000. 558p.
CHITARRA, M.J.F. Colheita e qualidade pós-colheita de frutos: Informe Agropecuário, Belo Horizonte, v.17, n.179. p.8-18. 1994.

CORVELLO, W.B.V.; VILLELA, F.A.; NEDEL, J.L.; PESKE, S.T. Maturação fisiológica de sementes de cedro (Cedrela fissilis Vell.). Revista Brasileira de Sementes, Brasília, v.21, n.2, p.2327, 1999.

DIAS, D.C.F. Maturação de sementes. Revista SEED News, Pelotas, v.5, n.6, p.22-25, 2001.

DONADIO, L.C.; NACHTIGAL, J. C.; SACRAMENTO, C. K. do. Frutas exóticas. Jaboticabal: FUNEP, 1988, 279p.

HERNÁNDEZ-UNZON, H.Y.; LAKSHMINARAYANA, S. Developmental physiology of tamarind fruit (Tamarindus indica L.). HortScience, Alexandria, v.17, n.6, p.938-940, 1982.

HULME, A.C. The biochemistry of fruits and their products. London: Academic Press, 1970. 618p.

INSTITUTO ADOLFO LUTZ. Normas analíticas do Instituto Adolfo Lutz. São Paulo: Instituto Adolfo Lutz, 1985. 533p

LEONHARDT, C.; TILLMANN, M.A.A.; VILLELA, F.A. MATTEI, V.L. Maturação Fisiológica de Sementes de Tarumã-de-Espinho (Citharexylum montevidense) (Spreng.) MoldenkeVERBENACEAE, no Jardim Botânico de Porto Alegre,RS. Revista Brasileira de Sementes, Brasília, v.23, n.1, p.100-107, 2001.

MARTINS, V. S.; SILVA, D.D. Maturação e época de colheita de sementes de Dalbergia nigra (Vell.) Fr. All. ex Benth. Revista Brasileira de Sementes, Brasília, v.19,n.1, p.96-99, 1997.

MORAIS, O.M.; SOUZA, R.T.; NAKAGAWA. J. Maturação de vagens, formas de secagem e qualidade fisiológica de sementes de Caupi (Vigna unguiculata (L.) Walp.). Informativo ABRATES, Pelotas, v.2, n.2, p. 62, 2001a.

MORAIS, O.M.; SOUZA, R.T.; NAKAGAWA. J. Maturação, formas de secagen e qualidade fisiológica de sementes de soja. Informativo ABRATES, Pelotas, v.2, n.2, p. 61, setembro 2001b.

NAKAGAWA, J.; CAVARIANI, C.; ZUCAREL, C. Maturação, formas de secagem e qualidade fisiológica de sementes de MucunaPreta. Revista Brasileira de Sementes, Brasília v.27, n.1, p.4553, 2005.

PANTÁSTICO, E.B. Postharvest physiology, handling and utilization of tropical and subtropical fruits an vegetables. Westport: AVI, 1975.560p.

REIS, R.B.; SALOMÃO, A.N. Efeito do grau de maturação de frutos na germinação de sementes de jenipapo (Genipa americana $\mathrm{L}$. (RUBIACEAE)). Informativo ABRATES, Pelotas, v.9, n.1/2, p.31, 1999.

RICHARDS, F.C. The quantitative analysis of plant growth. In: STEWARD, F.C (Ed.). Plant physiology: a treatise. New York: Academic Press, 1969, p.3-76.

WARRINGTON, L. J.; FULTON, T. A.; HALLIGAN, E. A.; SILVA, H. N. Apple fruit growth and maturity are affected by early season temperatures. Journal American Society Horticultural Science, Alexandria, v.124, n.5, p.468-477, 1999. 